\title{
ESTEREOTIPOS DE LATINOAMERICANOS EN LA PUBLICIDAD RADIOFÓNICA ESPAÑOLA
}

\section{LATINAMERICANS STEREOTYPES IN SPANISH RADIO ADVERTISING}

\section{AUTORA}

Ma Teresa Piñeiro Otero.

Universidad de Vigo. Pontevedra (España).

m.terepo@gmail.com

\section{RESUMEN}

El papel que desarrollan los medios de comunicación y la publicidad en el proceso de formación de la persona ha suscitado el interés hacia el tipo de representaciones sociales que éstos vehiculan. Un interés que ha propiciado la aparición de un relevante corpus teórico relativo a las representaciones mediáticas de los diversos grupos sociales; unos estudios en donde el medio radiofónico ha quedado relegado.

El objeto del presente artículo ha sido el de conocer el uso que la publicidad radiofónica española realiza de las diferentes representaciones de latinoamericanos, así como determinar el tipo de cualidades o atributos más frecuentes en la construcción de dichos estereotipos. Para ello se ha optado por llevar a cabo un análisis de contenido de la publicidad radiofónica presentada al Festival Publicitario de San Sebastián entre 1996 y 2002. 


\section{PALABRAS CLAVE}

Publicidad radiofónica- Estereotipos- Minorías

\section{ABSTRACT}

The paper that media and advertising develop in the person socialization process has aroused the interest to the type of social representations that these they use. This interest has favoured a notable theoretical corpus apparition relative to the diverse social groups media representations; radio has been forgotten in these studies.

Present article aims to know Spanish radio advertising use of Latin American different representations, as well as determine the kind of qualities or attributes more frequent in these stereotypes construction. It was used, on this study, a content analysis of radio advertising presented to San Sebastian Advertising Festival between 1996 and 2002.

\section{KEY WORDS}

Radio advertising - Stereotypes- Minorities

\section{ÍNDICE}

1. Introducción.

2. De las representaciones sociales a las representaciones publicitarias.

2.1 Los media y la publicidad en la construcción de representaciones sociales

3. El proceso de estereotipia en el medio radiofónico.

4. Metodología.

5. Estereotipos de latinoamericanos en el Festival de San Sebastián.

5.1 Caracterizadores de las representaciones de "latinoamericanos".

5.2 Principales estereotipos.

6. Conclusiones.

7. Bibliografía. 


\section{Introducción.}

Afirmar la injerencia de los medios de comunicación en el proceso de formación de la persona se ha convertido en una especie de lugar común en el ámbito de las representaciones mediáticas y publicitarias de los diferentes grupos sociales. En efecto, los medios de comunicación han modificado los procesos tradicionales de socialización, de construcción social de la realidad así como de la fundamentación de las identidades sociales (I gartua y otros, 1998).

Este papel que adquieren los medios de comunicación como agentes socializadores favorece la "contaminación" de los estereotipos sociales - construidos, consolidados y transmitidos generacionalmente dentro del endogrupo- por aquellos otros cuya creación y difusión responde a los intereses de un medio o unos medios concretos. Una circunstancia de especial relevancia si se parte del hecho de que van a ser estas representaciones, acordes con los intereses del medio o de sus anunciantes, las que terminen configurando el sistema de creencias e imaginario de una determinada sociedad.

La representación mediática y publicitaria de los diferentes grupos sociales ha generado un amplio corpus de investigación. Unos estudios que se han enfocado, fundamentalmente, en los estereotipos de género frente a las imágenes de otros grupos sociales y en su tratamiento por parte de la televisión (del Río, 1996), más que en el de otros medios de comunicación "clásicos" como la prensa o la radio.

De hecho, en lo que respecta a la investigación en torno a las representaciones publicitarias de los diferentes grupos sociales el medio sonoro aparece infrarrepresentado. Circunstancia que podría llevar a pensar que la radio acude a representaciones de grupos sociales más acordes con la realidad; no obstante los estudios llevados sobre este ámbito han confirmado la existencia de estereotipos 
sonoros similares a los de la televisión (Furham y Schofield, 1986; Furham y Thompson; 1998).

El presente artículo tiene por objeto conocer la utilización que la publicidad radiofónica española realiza de las representaciones de latinoamericanos, así como el tipo de características y atributos sobre los que se construyen dichos estereotipos.

Un análisis que va a utilizar el concepto de "latinoamericano/a" para denominar el conjunto de representaciones vinculadas a los habitantes de los diferentes países situados en el Caribe, América Central y Sudamérica. Una denominación que si bien siguiendo a Vargas Hernández (2000) puede considerarse reduccionista, dado que hace referencia a realidades nacionales y culturales muy diversas, es la más extendida para definir a este grupo.

\section{De las representaciones sociales a las representaciones publicitarias.}

En el ámbito de las representaciones sociales y, por ende, de su proyección en los medios de comunicación y publicidad, el concepto de minorías implica una "calidad" de ciudadanos más que una cantidad de los mismos (Barrios, 1996). De este modo se pueden considerar "minorías" grupos sociales numerosos como las mujeres, los incapacitados, los extranjeros... El hecho de pertenecer a uno de estos grupos sociales confiere al individuo una categoría social "desventajosa" y, por tanto, los convierte en víctimas de discriminación (Barrios, 1996).

En la actualidad no se conoce ningún caso de sociedad o cultura en la que, de alguna manera, no exista ninguna distinción entre un "yo" y un "otro", un "nosotros" y un "ellos" (Calhoun, 1994) que, con frecuencia, entraña un principio de discriminación. 
Profundizar en la concepción de minorías y su representación, ya sea en el imaginario social ya en los medios de comunicación, implica hacer referencia a los estereotipos sociales y -con ellos- al proceso de estereotipia social. Una aproximación que resulta compleja ante la multiplicidad de definiciones acuñadas para el fenómeno del estereotipo social tras su primera conceptualización, en 1922, por Walter Lippman. De hecho, se ha hablado de estereotipo social como:

"Una imagen ordenada y más o menos coherente del mundo, al que nuestros hábitos, gustos, capacidades, consuelos y esperanzas se han adaptado por sí mismos. Puede que no formen una imagen completa, pero son la imagen de un mundo posible al que nos hemos adaptado" (Lipmann, 2002, p. 93)

"La imagen compartida que existe en un grupo social relativa a las características atribuidas a los miembros de otro grupo social en cuanto miembros de ese grupo". (Cano, 1993, p. 269)

"La atribución de características generales a los grupos humanos grandes. No cabe duda que el contenido de los diversos estereotipos tiene sus orígenes en tradiciones culturales, que pueden estar relacionadas o no con experiencias comunes, pasadas o presentes, generalizadas en exceso". (Tajfel, 1981, p. 160)

Unas definiciones que subrayan el hecho de que el estereotipo en las ciencias sociales se configura como un concepto delimitado en torno a la relación de los individuos (o endogrupo) con el "otro" (exogrupo) y consigo mismo, o las relaciones entre los grupos y sus miembros individuales (Amossy y Herschberg, 2001, p. 34). En este sentido, el término estereotipo lleva implícito un proceso de generalización y simplificación, con frecuencia vinculado al prejuicio. 
La oposición binaria del "yo/nosotros" frente al "otro/otros" con frecuencia ha implicado el desarrollo de patrones de pensamiento fundamentados en la "negatividad" del "otro/s" "locate the other outside of the field of subjectivity as it were, as pure excess; notions of 'negativity' locate the other within the field of subjectivity as a constitutive exotic other". (Grossberg, 1996, p. 90)

Los estereotipos suponen resúmenes de la complejidad social; elementos básicos de economía cognitiva que permiten organizar y ordenar la gran cantidad de datos que el individuo recibe continuamente (Allport, 1971). Como resúmenes de la realidad, los estereotipos facilitan la comunicación y comprensión debido a su capacidad de generar una interpretación unívoca en la mente de las personas que pertenecen al mismo endogrupo.

El hecho de acuñar y utilizar estereotipos resulta tan frecuente que, la mayor parte de ellos, se llegan a asumir de un modo familiar y, a menudo, inconsciente (Quin y McMahon, 1997, p. 137). Esta circunstancia favorece "la formación e interiorización de una categorización social para incluir el yo -y operar como identificación social que produce la conducta de grupo" (Turner, 1990, p. 147); constituyendo una transferencia del ser al deber ser (Fernández, 1998, p. 34).

En el ámbito concreto de las representaciones de "latinoamericanos" resulta preciso hacer referencia a la existencia de un discurso hispanicista que implicó la construcción de conceptos como el Nuevo Mundo o las Américas; conceptos que han impregnado la representación de un "Otro" cuya concepción todavía pervive en las culturas europeas (Westwood, 1993).

Desde la perspectiva española algunos de los elementos implícitos en la representación social de los latinoamericanos, obviando la heterogeneidad presente en esta denominación, son los de "cariñosos y melosos", "simpáticos", "amables", "alegres", "bailan bien", "apasionados", "se dejan llevar por el corazón", "gente excepcional", "les gusta hablar", "están buenos"; otras características más negativas 
son las de "charlatanes", su necesidad de imitar a los españoles, "con subdesarrollo", "discriminados" o "colonizados" (Pérez-Grande y otros, 1999)

\subsection{Los media y la publicidad en la construcción de representaciones sociales}

El estudio de los estereotipos sociales está revestido en la actualidad de una gran complejidad debido a la diversidad social existente, sumada a la irrupción de medios de comunicación y publicidad en el proceso de estereotipia.

"Con frecuencia el público se forja a través de la televisión y la publicidad una idea de un grupo nacional con el que no hay contacto. (...) El impacto de estas representaciones resulta poderoso no sólo en el caso de los grupos de los que no se tiene un conocimiento efectivo, si no también de aquellos con los que se tiene contacto cotidiano o a los grupos a los que uno pertenece". (Amossy y Herschberg, 2001, p. 41).

Desde su primera conceptualización en el ámbito de las Ciencias Sociales, por Lippmann, el término estereotipo estuvo íntimamente ligado a los medios de comunicación. Unos medios que, pese a no ser creadores de estereotipos sociales per se, pueden reflejar y reforzar algunos contenidos de dichas representaciones. De hecho en sus mensajes algunas diferencias sociales difusas pasan a ser diferencias claras e, inclusive, se proponen diferencias donde no existían (De Andrés, 2002).

En el caso concreto de la publicidad ésta no sólo se limita a estimular la venta de productos y servicios sino que presiona a la sociedad con un modelo ideológico completo, dado el impacto acumulado del conjunto de asunciones culturales que forman un sistema integrado de creencias (Qualter, 1994, p. 89). 
Con la adopción del rol de productor cultural, la publicidad configura la realidad percibida, estableciendo sus propias normas y ampliando su alcance de los productos a los universos simbólicos a ellos asociados y, por extensión, a los imaginarios sociales.

\begin{abstract}
"[Los] (...) modelos apreciativos, que articulan informaciones y determinan actitudes son, de hecho, representaciones del imaginario social. Y la publicidad es uno de los principales generadores de estos modelos, que si bien se incorporan a la imaginería del consumo, también se integran a otras categorías de representaciones individuales y sociales: a la cultura personal y colectiva." (Costa 1992, p. 32).
\end{abstract}

En este sentido resulta preciso que la publicidad presente un mayor respeto por la diversidad, sobre todo desde la perspectiva de su papel en el proceso de socialización de las personas y del carácter - prácticamente- inmutable de estas representaciones sociales estereotipadas (Munné, 1989).

\title{
3. El proceso de estereotipia en el medio radiofónico.
}

Un análisis del corpus teórico relativo a la estereotipia publicitaria podría llevar a pensar en que el uso de estas representaciones de los diversos grupos sociales se trata de un fenómeno prácticamente exclusivo de los mensajes televisivos. Una concepción que responde al exceso de visualización del que adolece la televisión y que hace más plausibles sus estereotipos y - por ende- su contenido negativo.

No obstante, de la misma manera que los atributos visuales de los personajes televisivos o gráficos describen el tipo de rol que estos desempeñan, el medio radiofónico se va a valer de una serie de características sonoras para construir sus 
representaciones. En efecto, los personajes de los relatos radiofónicos van a definirse por medio de sus acciones y de sus atributos, entre los que se incluye el lenguaje (Betés, 2002, pág. 75)

La consideración del lenguaje como un atributo definidor de un personaje concreto, o del colectivo al que pertenece, nos remite a la imagen social de la lengua que incluye valoraciones, actitudes e imágenes. En este sentido, la dimensión valorativa-emotiva de la lengua puede provocar sentimientos de adhesión o rechazo del hablante; dimensión que toma mayor relevancia en aquellos mensajes publicitarios en los que las características lingüísticas y sociolingüísticas del protagonista nos remiten al "exogrupo" y, por tanto, activan preconcepciones existentes respecto a este.

La lengua de determinado grupo forma parte de su identidad social y, en consecuencia, los individuos reproducen determinadas características lingüísticas definiéndose como miembros del mismo (Tajfel, 1981). Por esta razón, la publicidad radiofónica construye determinados grupos sociales valiéndose de sus peculiaridades lingüísticas, prosódicas, fónicas, sociolingüísticas... 0, al menos, de la reproducción de aquellas características de tipo lingüístico y extralingüístico que son asociadas a los estereotipos sociales de dichas representaciones.

\section{Metodología.}

Si la publicidad se configura como uno de los agentes más influyentes en la sociedad contemporánea, constituye un marco de referencia fundamental para el análisis de las representaciones sociales de determinados grupos minoritarios.

En busca de conocer el tipo de representaciones que la publicidad radiofónica vehicula de los/as latinoamericanos/as se optó por el análisis de contenido como metodología de investigación. Un análisis de contenido para el que se estableció una herramienta de trabajo que, además de conocer los diferentes estereotipos reunidos 
bajo la denominación de "latinoamericanos", permitió profundizar en aquellas características y atributos sobre los que se construyen.

Para realizar dicho estudio fue preciso establecer un conjunto de anuncios radiofónicos con unas características similares; circunstancia relevante si se parte del hecho de que la publicidad radiofónica abarca diferentes tipologías de anuncios, de diversa constitución y calidad que dificulta un análisis de estas características. Razón que llevó a determinar como muestra de estudio aquellas cuñas radiofónicas presentadas al Festival Publicitario de San Sebastián; certamen de referencia en el mercado publicitario español que a partir de su edición de 2003 incorporó la participación del mundo latino.

Esta selección, compuesta por un total de 915 anuncios sonoros, concretó el estudio a un tipo de publicidad de mayor calidad que los mensajes radiofónicos habituales, y a un período de tiempo determinado: entre 1996-2002 (entre el año de creación del galardón de radio y la última edición del certamen antes de su apertura al ámbito iberoamericano).

El hecho de acotar dicha muestra al período del festival con participación exclusiva de la publicidad "made in Spain" configura a sus mensajes como exponentes básicos de las concepciones e ideas que, en el contexto español, existe de los /las latinoamericanos/as. Un análisis del "otro" desde la perspectiva de la cultura mayoritaria española.

\section{Estereotipos de latinoamericanos en el Festival de San}

\section{Sebastián.}

El análisis de las representaciones sociales existentes en la publicidad radiofónica del Festival de San Sebastián ha llevado a considerar la existencia e diversos 
estereotipos que pueden ser incluidos bajo la denominación de latinoamericanos en función de su origen y, dentro de éste, de la mayor o menor positividad de las características y/o valores sobre los que se construyen.

Unos estereotipos que se corresponden, fundamentalmente, con personajes masculinos siguiendo una tendencia global de infrarrepresentación de las voces femeninas en toda la muestra. De hecho, los personajes femeninos cuyas características remiten a este grupo suelen aparecer como contrapunto en la interacción lingüística con otro u otros personajes masculinos.

Ejemplo $1^{1}$.

* Sprite presenta la radionovela "Devuélveme el rosario de mi madre". Capítulo 1724. Resumen del capítulo anterior: Rosa Ma Elena Eugenia, ha descubierto la traición de Darío Carlos Jesús y se dispone a enfrentarse a él.

- Canalla, canalla, tres veses canalla. Anoche te vi bailando el Mambo con Clara Fernanda y vi como la abrasabas, y ella es mi hermana, desgrasiado traidor. Eres horrible. Nunca te lo dije, tu aliento es fétido, te huele la boca, los pies y eres el hombre más feo del mundo.

- * No llores más mi amor. Mira lo que te he traído.

- * iSprite!

- * Sí, mi vida. Toma, bebe.

\footnotetext{
${ }^{1}$ El parlamento de los personajes caracterizados como "latinoamericanos" será, precedido, en los ejemplos aportados, por un asterisco $(*)$.
} 
- * Mi prínsipe, cuanto me cuidas, generoso, eres el hombre de mi vida. Quiero ser la madre de tus hijos.

No creas todo lo que digan los anuncios, y menos lo que digan las novelas. Ninguna bebida hase milagros, porque la imagen no es nada. Obedece solo a tu sed. Sprite.

\subsection{Caracterizadores de las representaciones de} "latinoamericanos".

A la hora de abordar las representaciones de "latinoamericanos" presentes en la publicidad objeto de estudio, resulta preciso señalar que este clasificador implica, de un modo más o menos explícito, la existencia de diferencias de carácter cultural y lingüístico (esenciales para su construcción e identificación sonora).

La utilización de personajes latinoamericanos en la publicidad radiofónica está relacionada con las particularidades vocálicas de este colectivo - que cuenta con características fónicas, prosódicas y ligüísticas propias- y el reconocimiento instantáneo de esta construcción sonora con el objeto referido debido a la familiaridad de dichas representaciones. Una construcción sonora que puede presentar elementos comunes al colectivo de latinoamericanos en general, como sucede con determinados rasgos fónicos como el seseo, o identificar a un grupo concreto de personajes, es el caso del rehilamiento de la " $y$ " como elemento definitorio de los argentinos.

A la hora de construir las representaciones de latinoamericanos, así como los espacios y el tipo de interacciones en los que se insertan, la publicidad radiofónica suele acudir a una serie de elementos de carácter cultural que suscitan un reconocimiento instantáneo en su audiencia. Unos elementos que no tienen que corresponderse, necesariamente, con rasgos culturales del grupo representado, sino 
con aquellos que el público reconoce como tales. Es el caso, por ejemplo, de la vida pausada de los caribeños o sus prácticas de hechicería.

\section{Ejemplo 2.}

- * Soy la Suma Sacerdotisa del Vudú-Má-Bámalú, bienvenido a mi consulta mágica, tú mandas, mi amol!

- Escolti yo es que odio a alguien, ¿sabe? Alguien que me ha hecho sufrir mucho, ¿puede usted ayudarme?

- * Por supuesto, mi amol, le clavaré unos alfilere'. Pero necesito una prenda, algo, una foto...

- ¿Una foto? ¡Tenga!

- „Us! ¡Pero si e Dietéfano!

- Es que yo soy el sosi 111 del Barça, ¿sabe? Y aún no me he conseguido olvidar de aquellos goles que nos metía. Uyuyuyuyuy,

Cada AS te regala tres láminas de los grandes jugadores del Real Madrid. Para que completes el libro de la Historia gráfica del club merengue de AS. Tanto si eres seguidor del Real Madrid, como si no.

- Escolte, también tengo fotos del Pirri, el Puscas y el Gento. ¿Usted no hace descuentos para hacer el vudú a grupos?

Además de los rasgos de carácter vocálico y los elementos de tipo cultural, resulta particularmente interesante en la construcción de estos personajes el tipo de producto anunciado. Un ejemplo de ello es la vinculación del ron al estilo de vida de un país o a otro tipo de elementos presentes en el imaginario social sobre un determinado grupo social, como sucede con los venezolanos y las telenovelas. 


\section{Ejemplo 3}

* Capítulo 1. Abigail del Mar concose a Roberto Alejandro.

- * Bailamos chama?

- * No grasias.

- Ya le vale, pero si solo es un ratito.

- * No chamo, déjame.

- Y me aseptas una copa de ron?

- * Depende de que ron.

- * Chama, eso no te lo puedo desir, nos están oyendo toda España.

Música. Los venezolanos son listos. Nos enviaron lo peor, los culebrones y se quedaron lo mejor, Ron Pampero. Añejado durante años en barricas de roble y ocultado, a propósito durante mucho tiempo. Ron añejo Pampero, habrá que descubrirlo.

Estas diferencias han sido fundamentales para la caracterización de las diversas representaciones de latinoamericanos. Una caracterización potenciada, en la mayor parte de los casos, con el uso del humor como formato expresivo.

De facto, en el ámbito concreto de la publicidad radiofónica presentada al Festival Publicitario de San Sebastián, el humor ha constituido uno de los principales ingredientes de la creatividad. Más del $62 \%$ de los anuncios radiofónicos de dicho certamen cuentan con el humor como principal formato expresivo, y se han podido destacar elementos cómicos en el resto de la muestra. 
Esta relevancia del humor en los mensajes analizados ha permitido a la publicidad acudir a determinadas representaciones negativas, o rasgos vinculados a éstas con relativa impunidad. En efecto, siguiendo a Possenti (2002) los estereotipos en los chistes se comportan como un efecto necesario de la relación interdiscursiva, especialmente en aquellos casos en que dicha relación es polémica.

\subsection{Principales estereotipos.}

A partir de estos elementos caracterizadores - rasgos de carácter vocálico, de tipo cultural o su vinculación a un determinado producto- se ha podido determinar la existencia de diversas tipologías de representaciones dentro del grupo de personajes latinoamericanos.

Unas representaciones, construidas en función de su atención a uno o más caracterizadores, entre las que se pueden señalar:

Argentinos. Grupo de personajes caracterizado por determinadas particularidades fónicas, entre las que destacan el citado rehilamiento de la " $y$ ", prosódicas y discursivas. Estas particularidades discursivas, como su fluidez verbal, han propiciado la consolidación del estereotipo de argentino en determinadas profesiones como la de psicoanalista (y determinadas variantes como psicólogo, psiquiatra, terapeuta...).

\section{Ejemplo 3.}

- Y ahora quiero que todas repitan conmigo: me lo merezco.

- Me lo merezco.

- * No me voy a sentir culpable, me lo voy a comprar.

- Me lo voy a comprar. 
- * Porque me lo merezco.

- Porque me lo merezco.

V.O. Convénzase de una vez y concédase un capricho. Con Supercompra BBV dispone de un crédito inmediato para comprar lo que quiera y pagar hasta en tres años. Supercompra BBV del Banco Bilbao Vizcaya.

Otra de las profesiones habitualmente vinculadas a esta representación es la de futbolista.

Mejicanos. El elemento diferencial de dicho grupo es su peculiar prosodia arrastrando las vocales, un vocabulario propio, así como determinadas elementos asociados a su cultura como los mariachis o su gastronomía. Dos elementos que se conjugan para publicitar servicios de restauración típicos.

Ejemplo 4.

- * (Ovación) ¡Bang, Bang! Y ándele mis cuateees. Pues si no donde está mi ejército de machacoteees.

- * Pues si donde va ser, patróoon. En el rancho de Villaverde. Que tiene treinta clases de tequila, y las mejores comidas mejicana'.

- * Buenoo, Restaurante Rancho, en Villaverde. ;Bang, Bang! ;Y no se me revolucionen, hombreeee! (Aplausos).

Venezolanos. La representación de este grupo está vinculada, además de a sus particularidades lingüísticas y fónicas, a las telenovelas. De hecho, diversos anuncios han utilizado las telenovelas como elemento distintivo de este colectivo debido a su reconocimiento como propio de la cultura venezolana (cuestión sobre la que ironizan alguna de las piezas publicitarias analizadas). Un ingrediente característico que, en 
algunos anuncios, ha sido potenciado por la tipología de producto publicitado, como es el caso del ron.

\section{Ejemplo 5.}

* Capítulo 3. Lourdes Topacio queda embarasada.

- * Abigail del Mar te has enterado lo de Lourdes Topacio?

- * No chamo ¿que pasó?

- * Está esperando un hijo de su propio hermano.

- No puedo creerlo, chamo! Si eso solo pasa en las telenovelas que hasemos para España.

Música. Los venezolanos son listos. Nos enviaron lo peor, los culebrones y se quedaron lo mejor, Ron pampero. Añejado durante años en barricas de roble y ocultado, a propósito durante mucho tiempo. Ron añejo pampero, habrá que descubrirlo.

Cubanos. En la caracterización de estos personajes se ha utilizado su particular prosodia, determinadas coletillas como "mi amor", pero - sobre todo- elementos de carácter cultural (más o menos negativos), o político. En efecto, Fidel Castro constituye uno de los personajes "celebridad de la vida real" de la muestra.

\section{Ejemplo 6.}

* Grandes acontesimientos de la actualidad, patrocinados por Anís del Mono.

- Nos encontramos en la barbería presidencial de La Habana donde vamos a asistir al afeitado de la barba de Fidel Castro patrocinado por Anís del Mono. Presidente, es cierto que va a ponerse un tatuaje con la efigie de Anís del Mono en la mejilla derecha. 
- * (Imitando acento cubano) Bueno, tu sabe. La primera popue'ta era ponérmela en la nalga izquierda. Pero siempre digo que hay que dar la cara... (ovaciones)

- * Y en este momento, señoras y señores, hasen entrada, en la barbería, las esculturales bailarinas del ballet Tropicana sujetando botellas de Anís del Mono sobre cabesa. Qué monas son.

En cualquier momento, en cualquier lugar, Anís del Mono.

- * (Imitando acento cubano) Vamoh a ver con, cuidadito, cuidadito. No me vayas a chingar la mejilla, tu sabes. Como me chingues la mejilla, te vo a cortar a ti lo que tu suena, vale tu!

Dominicanos. Cuya construcción se fundamenta en una dicción pausada, acorde con un estilo de vida tranquilo, lejos del estrés cotidiano de la vida occidental (entendiendo occidental como española). Estas representaciones están ligadas, en la muestra, a un producto concreto: el ron.

Ejemplo 7.

¿Qué pasaría si en el Caribe se tomasen la vida tan en serio como el resto de los mortales?

- * Segunda Uve a ras, frenando mucho voy a tres, a cuarta izquierda, ojo agua, cuidado pelícano, lástima pelícano, reduce ahora a dos, de quinta a cuarta a c, esquivando al bus, o a tres, uno menos, saliendo de mar abierto a ras, orilla cerca, reduce a dos, ojo picador, familia de luto, atento a la guire en la tumor a tres, llegando a puerto, frenando muebles.

Si nos tomásemos la vida tan en serio, no tendríamos Malibú.

- * Lanzando ancla. A ras. 
Entre las imágenes de los diversos colectivos de latinoamericanos vehiculadas en la publicidad radiofónica, en función del país de pertenencia, resulta preciso destacar el estereotipo de caribeños (que abarca representaciones de dominicanos y cubanos) debido a la riqueza con la que han sido caracterizados en la muestra de estudio.

\subsection{Estereotipos de caribeños en la publicidad radiofónica} española.

El estereotipo de caribeño se suele construir sobre la concepción de dicha cultura como una panacea de tranquilidad, de una vida a un ritmo más pausado frente la estresante vida occidental. Para ello, la caracterización de estos personajes se basa en una dicción pausada y prosodia "melodiosa" así como en su localización en ambientes tranquilos. Circunstancia que los hace destacar en una selección de cuñas en la que este tipo de características no son las más frecuentes.

Una representación que se completa con otro tipo de rasgos culturales o productos que conforman el imaginario social español sobre los caribeños: su carácter "sabrosón", la música o el ron.

Ejemplo 8

(Música de salsa)

- *ye muchacho

- * Usted dirá

- ¿Ya tu entiendes de sabó?

- * ¿Qué sabó?

- * ¡El mejó!

- * Se come, se bebe...

- * Se fuma, padrino

- * ¿Y qué es? 
- Canela

- * ¿Cómo me dises?

- *Vegafina

- ¿Y es sabroso?

- * Es goloso

- ¿ ¿Cómo e? ¿E un purito?

- * Casi amigo; un sigarrito

- * Vegafina, ¿y e rico?

- * No ti maginas

- * ¿Puedo probarlo?

- *a tu sabrás

Vegafina el cigarrito más puro.

La negatividad de este estereotipo se manifiesta en dos tipos de representaciones; aquellas vinculadas con la santería y/o la magia negra y aquellas que vinculan a las mujeres caribeñas con el turismo sexual. En los últimos años, y dada la continua "importación" de jóvenes caribeños como acompañante-pareja, se ha desarrollado un estereotipo vinculado a los hombres: el del "parásito"; estereotipo presente en la publicidad radiofónica de la muestra.

\section{Ejemplo 9}

- * Oye, mi reina, quiero hacerte el amor.

- Pero, ¿ tú no eres amigo de mi nieto?

- * Mira mi único amigo es el amor. Que, hacémoslo ya, aunque sea de noche. Quiero vivir contigo para toda la vida 
- Ay, pero si a mi ya me queda muy poquita vida

- (A.c.) Mira, tu sabes, mi reina, mi amor va a ser eterno

Ya conoces a los parásitos de la tierra, ahora calle 13 te presenta a los que vienen del espacio. Hoy domingo 13 a partir de las 21 horas especial "Parásitos alienígenas". Calle 13, el canal de suspense y acción que encontrarás en Canal Satélite Digital, Quiero y tu operador de cable.

La importancia que adquiere el colectivo de caribeños dentro de las cuñas analizadas se debe, fundamentalmente, a su vinculación con el ron. En efecto, las limitaciones legales a las que está sujeta la publicidad de bebidas alcohólicas en España, ha permitido a la radio postularse como el medio publicitario por excelencia de dicha categoría de productos.

Una situación que ha potenciado la presencia, en los anuncios radiofónicos, de personajes pertenecientes a diferentes minorías culturales: caribeños-ron, mejicanostequila o rusos-vodka (entre otros).

\section{Conclusiones.}

El hecho de que los mensajes publicitarios vehiculen y potencien determinadas representaciones sociales existentes en el imaginario social y cultural de una determinada colectividad supone un elemento de interés, tanto desde la perspectiva comunicativa como desde su persistencia en el endogrupo. Representaciones que, debido al cometido último de la publicidad, suponen una aproximación interesada y sesgada del "otro" (exogrupo). 
El tratamiento que la publicidad da a los estereotipos sociales ha supuesto el centro de atención de numerosos estudios, entre los que resulta patente una infrarrepresentación del medio sonoro. Una menor presencia de la radio que, lejos de corresponderse con la ausencia real de dichos estereotipos, guarda relación con el modo de recepción de sus mensajes.

En efecto, la publicidad radiofónica española vehicula diversas representaciones que pueden ser consideradas parte de la denominación de "Iberoamericanos". Estereotipos que, dada la esencia sonora del medio, son construidos a partir de las particularidades vocálicas de los personajes pertenecientes a dicho colectivo; una caracterización que se completa con la referencia a elementos de carácter cultural e - inclusive- con el tipo de producto anunciado.

Estas representaciones son definidas desde la perspectiva de la sociedad española y, por tanto, redundan en aquellos elementos que el público objetivo reconoce como propios de los diferentes colectivos. De este modo, el oyente puede distinguir entre personajes mexicanos, cubanos, dominicanos, venezolanos o argentinos.

Entre las imágenes de los diversos grupos de latinoamericanos vehiculadas en la publicidad radiofónica destaca el de caribeños (que incluye diversas nacionalidades) debido a su particular caracterización en la publicidad analizada. Un estereotipo que, en ocasiones, presenta una caracterización negativa que es suavizada con la utilización del humor como formato expresivo.

En definitiva, el análisis de los estereotipos de minorías más habituales en la publicidad radiofónica presentada al Festival Publicitario de San Sebastián destaca una variedad en las representaciones que pueden ser englobadas dentro del clasificador "latinoamericano". Unos estereotipos que se construyen en el ámbito sonoro a partir de una serie de elementos reconocidos como propios de este grupo y que son potenciados con el uso del humor como formato expresivo. 


\section{Referencias.}

ALLPORT, Gordon W. (1971). La Naturaleza del Prejuicio. Eudeba. Buenos Aires. (Versión Original 1954).

AMOSSY, Ruth y HERSCHBERG, Anne P. (2001). Estereotipos y clichés. Eudeba. Buenos Aires.

BARRIOS, Leoncio (1996). "Re-presentación de las minorías sociales en los medios" en Comunicación: Estudios Venezolanos de Comunicación, no 22. Pág. 48-52.

BAR-TAL, Daniel (1994). "Formación y cambio de estereotipos étnicos y nacionales. Un modelo integrado" en Psicología Política, no 9. Pág. 21-50.

BETÉS, Kety (2002). El sonido de la persuasión. Relatos publicitarios en la radio. Universidad Cardenal Herrera-CEU. Valencia.

CALHOUN, Craig (1994). Social Theory and the politics of Identity. Blackwell. Cambridge.

CANO, J osé I gnacio (1993). Los estereotipos sociales. El proceso de perpetuación a través de la Memoria Selectiva. Tesis de Doctorado. Universidad Complutense de Madrid.Madrid, España.

COSTA, Joan (1992). Reinventar la Publicidad. Reflexiones desde las Ciencias Sociales. Fundesco. Madrid.

DE ANDRÉS, Susana (2002). Estereotipos de género en la publicidad de la Segunda República Española. Crónica y Blanco y Negro. Tesis de Doctorado. Universidad Complutense de Madrid. Madrid. 
DEL MORAL, María Esther (2000). "La publicidad y su contribución a la construcción de los nuevos modelos de mujer y de hombre" en Gerardo PASTOR, Ma Rosa PINTO y Ana Lucía ECHEVERRI: Cultura y medios de comunicación: actas del I// Congreso Internacional. Servicio de Publicaciones de la Universidad Pontificia. Salamanca.

DEL RíO, Pablo (1996). "Building identities in a mass-communication world: a commentary on Steven Mile's 'The cultural capital of consumption"' en Culture and Psychology, oㅡ 2. Pág. 159-172.

FERNÁNDEZ, Juan (1998). Género y sociedad. Pirámide. Madrid.

FURHAM, Adrian y SCHOFIELD, Sandra (1986)." Sex role stereotyping in British radio advertisements" en British J ournal of Social Psychology, no 25. Pág. 165-171.

FURHAM, Adrian y THOMSON, Louise (1999)." Gender role stereotyping in advertisements on two British radio stations" en Sex Roles, vol. 40, o 1-2. Pág. 153-165.

GIDDENS, Anthony (1995). Modernidad e identidad del yo. El yo y la sociedad en la época contemporánea. Ediciones Península. Barcelona.

GONZÁLEZ LOBO, María A. (1991). El consumidor de los noventa. JWT. Madrid.

GROSSBERG, Lawrence (1996). "Identity and Cultural Studies: is that all there is?" en Stuart HALL, Paul DU GAY. Questions of Cultural Identity. Sage. Londres. 
IGARTUA, Juan José y otros (1998). "Indicadores culturales y construcción de estereotipos en films de ficción" en Comunicación y Cultura, no 5/6. Pág. 43-56.

JAYME, María y SAU, Victoria (1996). Psicología diferencial del sexo y el género. Barcelona.

LIPPMANN, Walter (2002). La Opinión Pública. C. de Langre. Madrid. (Versión Original 1922).

MUELA, Clara (2001). La publicidad radiofónica en España. Ediciones Universitarias. Madrid.

MUNNÉ, Frederic (1989). "Prejuicios, estereotipos y grupos sociales" en Ángel RODRÍGUEZ y Julio SEOANE (coords.): Creencias, actitudes y valores. Alhambra Universidad. Madrid.

PÉREZ-GRANDE, María Dolores, GARCíA DEL DUJO, Ángel y MARTín GARCíA, Antonio Víctor (1999). "Prejuicios, estereotipos y otras profecías autocumplidoras" en Pedagogía Social, no 3. pp. 125-146.

POSSENTI, Sirio (2002). "Estereotipos e identidad en los chistes" en Cuiculico, vol. 9, no24.

QUALTER, Terence H.(1994). Publicidad y democracia en la sociedad de masas. Paidós. Barcelona.

QUIN, Robin y MCMAHON, Barrie (1997). Historias y estereotipos. La Torre. Vizcaya. 
TAJ FEL, Henri (1981): Grupos humanos y categorías sociales. Herder. Barcelona.

TURNER, J ohn C. (1990). Redescubrir el grupo social. Morata. Madrid.

VARGAS HERNÁNDEZ, José Guadalupe (2000). "Algunos Mitos, Estereotipos, Realidades y Retos de Latinoamérica" en Cinta de Moebio: Revista Electrónica de Epistemología de Ciencias Sociales, no 8.

WESTWOOD, Sarah y RADCLIFFE, Sally (1993). "Gender, racism and politics of identities in Latin America" en Sarah WESTWOOD y Sally RADCLIFFE: Viva: women and Popular Protest in Latin America. Routledge. Londres.

YOUNG, Kimball (1974). Psicología social. Paidós. Buenos Aires. 